\title{
COMMENTARY
}

\section{Cultural policy in the coalition years: Laissez-faire regulation, the public spending squeeze and the drive to digital}

Guy Starkey*

\section{Introduction}

Radio, so often described by academics as the "invisible" (Lewis \& Booth, 1989), "Cinderella" (Halesworth, 1971, pp. 189-191) or even "forgotten" medium (Pease \& Dennis, 1994), has enjoyed a relatively settled period under the coalition government. There has been no crisis of confidence over ethical and legal issues, as exposed in the press by Leveson and the police operations, Elveden, Tuleta and Weeting. There have been few headline-grabbing (if difficult-to-evaluate) initiatives like local television, as exemplified by London Live or Made in Tyne \& Wear, and no government-rocking conflicts of interest as spectacular as that over the ownership of BSkyB. Nor indeed has there been any game-changing reorganisation of public funding, similar to the Arts Council's lists of winners and losers. Yet, as is so often the case, radio remains a significant, but largely, ignored medium. In terms of government policy, it has suffered mixed fortunes under the five years of the coalition.

Official listening figures continue to confirm recent trends in radio's fortunes. If radio grabs little of the media limelight, it remains a medium with an enviable ubiquity. It may have been slow to win audiences among younger people as large as when it broke new music and provided the kind of escapism sought by youth in the 1960s and 1970s. However, a weekly reach of 90 per cent of the $15+$ adult population, and more than a billion $(1,025,971,000)$ hours listened by adults each week (Radio Joint Audience Research Limited [RAJAR], 2014) represent an enviable achievement in a world more mediatised now than ever before - in which print, broadcast and online media vie with recorded and downloadable formats, electronic gaming and social networking for a credible attention share. Radio is an established part of many people's lives, embedded in their daily routines, albeit as a sought-after source of information and entertainment, or as consumed passively as a background to tasks which require primary attention - such as driving, ablution, domestic or professional chores and so on (Crisell, 1994, pp. 6-11).

So, in the absence of great controversy, high-profile government initiatives or dramatic institutional change, radio still matters to millions of ordinary people - consumers and citizens, audiences of listeners. However, the coalition's policies have done little to safeguard it against economic pressures which have had the effect of diminishing its potential or to release it from constraints on its ability to evolve.

*Email: guy.starkey@sunderland.ac.uk 


\section{Laissez-faire regulation}

The economic arguments, which convinced the previous Labour administration that regulation of commercial radio should be the lightest since its introduction in 1973, have continued to prevail. The current regulator, Ofcom, has persisted in pursuing policies that favour (even encourage) consolidation within a sector seemingly intent on homogenising its output as much as possible. This has resulted in a dearth of truly local radio outside the BBC and the voluntary, community sector. Where once regulation ensured local ownership and local content production, the post-Communications Act 2003 regulatory focus on output, as opposed to process, has continued unabated. The argument that the most economically fragile of local commercial radio stations, which are far smaller in coverage area than any envisaged when commercial radio was proposed by the Conservatives in their 1970 general election manifesto, would close through insufficient revenue, has continued to prevail under the coalition, absolving even the largest and most profitable stations of most of their original public service commitments.

This has continued to have sweeping institutional consequences for the sector. The biggest and most bullish of UK radio groups, Global Radio, continued rebranding once locally owned and operated radio stations, in order to build quasi-national brands with synergies in marketing and business-to-business sales potential intended to maximise income at the expense of local diversity and distinctiveness. Many of these stations enjoyed local heritage dating back to the 1970s and 1980s. Twenty-nine local stations had been rebranded as Heart in 2008, and in June 2010 production practices at the 33 stations then operating as Heart were reorganised into just 15 regional "super station" news and programming "hubs". This led, at a stroke, to the loss of 200 freelance and staff positions (Starkey, 2015, pp.158-159), hardly healthy for a sector renowned for job insecurity. That was particularly harmful to individuals as the second downturn of the double-dip recession approached. However, removing production practice from an editorial area and replacing it with a simulated localness that uses the potential of radio's invisibility to disguise out-of-area local content production does little to promote empathies between audience and producer, or medium and community.

In 2011, Global's aggressive policy of maximising profit at the expense of true localness continued as it rebranded an additional nine regional and local stations by then in its ownership as Capital. In 2012, as if further evidence were needed of the capacity of history to be repeated, the group announced the purchase of the portfolio of regional FM stations being disposed of by the Guardian Media Group. It subsequently made known a deal with an Irish media company to circumvent the limited constraints of a monopolies and mergers ruling on the purchase. So the wholesale rebranding continued, turning Smooth into a third quasi-national brand which also replaced Gold on all but four of Global's local AM transmitters.

Table 1 shows how one effect of aggregating previously locally defined audiences as Heart, Capital and Smooth has been to build nationally significant audience data to rival that of the BBC. This strategy, tolerated by regulator and government alike, amounted to a mass homogenisation of commercial radio, apparently driven only by the profit motive. As a result, the last vestiges of local distinctiveness have now all but gone from all those radio stations. Localness is now confined, in most cases, to a regulatory minimum of isolated local programmes in daytime, local commercials (that local advertisers, and even the centralising management would be loathe to lose) and increasingly diluted local news, much of it produced outside once distinctive editorial areas (Starkey 2015, pp. 163-164).

By little more than a stroke of luck, rather than any government policy initiative, the UK's second largest radio group, Bauer Media, is far more careful than Global in its respect for both brand heritage and distinctiveness. Despite its German ownership, it continues to resist most temptations to re-brand and over-concentrate production on the many heritage stations it has 
Table 1. Headline radio listening data for the UK's most-listened-to radio services, Q3 2014.

\begin{tabular}{lcc}
\hline Weekly & Reach $(1000 \mathrm{~s})$ & Share $($ per cent) \\
\hline BBC Radio Two & 15,014 & 17.0 \\
BBC Radio Four & 10,621 & 11.9 \\
BBC Radio One & 10,550 & 6.9 \\
Heart & 9075 & 6.6 \\
Capital & 7343 & 3.9 \\
BBC Radio 5 Live & 5809 & 3.8 \\
Classic FM & 5199 & 3.6 \\
Smooth & 4692 & 3.5 \\
\hline
\end{tabular}

Source: RAJAR.

acquired, mainly in the North of England and Scotland. Fortunately, a number of other (although much smaller) commercial radio groups still remain. These include UKRD, Quidem, Lincs FM, UTV Media, Orion Media and Tindle, which provide some element of diversity in local commercial radio.

By contrast, community radio, introduced under Labour, continues to grow under Ofcom's rolling programme of inviting applications from potential non-profit-making operators and awarding licences in a manner reminiscent of the original commercial sector "beauty contest" licence awards. This amounts to more governmental laissez-faire as financial support for the community sector is extremely limited. In contrast, given the well-documented track record of community radio to unlock potential in its volunteers and promote self-help initiatives among the communities they serve, a more proactive approach to this small army of unpaid volunteers could relatively easily produce a range of social and cultural dividends (Lewis \& Booth, 1989). Much tighter control of community radio means that when it is done well it can indeed produce the kind of locally produced content that reflects local diversity and encourages local participation. These stations cannot be bought and sold, and their income from advertising or any other single source is restricted. However, using community radio and the essentially exploitative nature of volunteering as a fig leaf to replace what was once paid work and to absolve commercial radio of its formerly rigorously policed public service obligations can easily be perceived as both disingenuous and as a betrayal of the listener, whose access to professionally produced local radio content is now very limited when compared to even the fledgling commercial radio network of the early 1980s.

\section{A licence-fee squeeze}

Sandwiched between the 10-yearly Royal Charter renewals of 2007 and 2017, the coalition's influence on the BBC has been limited to the financial control of the otherwise arms-length Corporation that British governments have enjoyed since the receiving licence fee was first set in the 1920s. Extraordinarily, and with little public debate, the then Director-General, Mark Thompson, conceded to a real-terms cut in the BBC's income of 16 per cent within weeks of Cameron coming to power in 2010. This was achieved through the freezing of the licence fee and the removal of long-standing Foreign and Commonwealth Office funding for the World Service. Abandoning its usually sceptical stance on government policy, this once fiercely independent organisation accepted unquestioningly the fashionable coalition rhetoric on the budget deficit and its desire to eliminate it, in part at the expense of public spending. Despite the clearly ambassadorial role of the BBC World Service, instead of the taxpayer it became the 
licence-fee payer who would bear the cost of providing the service. This may seem like a mere technicality, but it contributed significantly to the coalition's deliberate squeeze on publicly owned and funded broadcasting.

Nonetheless, the BBC has achieved its partial decentralisation to "The North" by moving Radio 5 Live and some television to Media City UK, Salford. The rationalisation of its London operation with the closure of the iconic former World Service headquarters, Bush House, the departure from White City and the extension to Broadcasting House in Westminster, has undoubtedly brought efficiency savings, but not without cost. The disastrous failure of the BBC's digital content management system initiative (Parliament, 2004) and the other selfinflicted scandals over past staff misdemeanours and management pay-offs cannot be blamed on the coalition, even if the impact of the licence-fee settlement on programme budgets can. The effect of the funding squeeze has inevitably impacted on programme-making. Local radio has also been hit, with the Orwellian "Delivering Quality First" agenda imposing on individual stations programme sharing at times of the broadcasting day previously characterised by locally originated and locally orientated programming.

\section{Digital development}

One positive aspect of coalition policy towards radio has been to encourage both the BBC and any willing participants in the commercial sector to make a renewed effort in the long process of, if not actually switching off analogue transmissions, at least managing radio listeners' migration to digital transmissions in a more timely manner. In 2010, a new Digital Radio Action Plan was announced to achieve just that. While the UK remains a world leader in developing a popular digital radio offer and attracting significant numbers of listeners to it, progress has been slow, as demonstrated in Table 2. Unlike in television, where the threat of analogue transmitter switch off actually meant there would be nothing left to watch on an old, analogue-only receiver, in radio future pirates could easily exploit the characteristics of cheaper and more easily portable FM transmitter equipment and step in to fill the vacuum of the otherwise empty FM band. The Department of Culture, Media and Sport (DCMS) strategy has been to bring a renewed vigour to the Digital Audio Broadcasting (DAB) transmitter roll-out to improve overall coverage and the robustness of signals in the areas of weakest reception.

In October 2014, culture minister Ed Vaizey told the audience at the annual Radio Festival that progress was being made on the development of the transmitter network and that the previous month a record 246,000 cars were fitted with digital radio as standard - 58 per cent of all new car registrations. He was planning to hold a "digital dashboard summit" in 2015 to investigate the state of the art on in-car connectedness, in which radio would play a significant part (DCMS, 2014). This consistent, but inevitably plodding approach, however, relies on the BBC and commercial DAB multiplex licensees to invest their own money, as opposed to government funding, on extending coverage: the Digital Radio Action Plan remains long on promise and short on delivery, given the limited progress made in its first four years.

Table 2. Digital radio listening platform data for all UK radio, Q1 2014.

\begin{tabular}{lcccc}
\hline $\begin{array}{l}\text { Share of radio } \\
\text { listening per cent }\end{array}$ & $\begin{array}{c}\text { On any digital } \\
\text { platform }\end{array}$ & $\begin{array}{c}\text { On } \\
\text { DAB }\end{array}$ & $\begin{array}{c}\text { Through any digital television platform } \\
\text { (Sky, Freeview or Freesat) }\end{array}$ & Internet \\
\hline 2014 Q1 & 36.6 & 23.7 & 5.0 & 6.4 \\
2008 Q4 & 18.3 & 11.4 & 3.2 & 2.0 \\
\hline
\end{tabular}




\section{Conclusion}

Undoubtedly some good progress has been made over digital migration during the coalition years, and the BBC has acquired and occupied some exciting new production space. Yet, the period has otherwise been one of retrenchment or stagnation. The laissez-faire attitude to commercial radio regulation and the failure to safeguard professionally produced, advertising-funded local content production was doubtless predictable given the Conservatives' dominance in the government, although, ironically, the original public service remit of Independent Local Radio was of that party's making. It was Labour who presided over the last significant relaxation of regulation in the sector, with the introduction of the Communications Act 2003 and Ofcom. However, if such a downward spiral in aspirations for the sector is to be halted - or even reversed - it is probably another government that has to step in and act.

\section{Disclosure statement}

No potential conflict of interest was reported by the author.

\section{References}

Crisell, A. (1994). Understanding radio. London: Routledge.

Department of Culture, Media and Sport. (2014). Ed Vaizey's speech at the Radio Festival 2014. London: Author. Retrieved October 15, 2014, from https://www.gov.uk/government/speeches/ed-vaizeysspeech-at-the-radio-festival-2014

Halesworth, B. (1971). 'Radio - the Cinderella medium' in educational broadcasting international (Vol. 5), number 3. London: Wynn Williams.

Lewis, P. M., \& Booth, J. (1989). The invisible medium: Public, commercial and community radio. London: Macmillan.

Parliament. (2004). BBC's digital media initiative a complete failure. London: Commons Select Committee. Retrieved November 17, 2014, from http://www.parliament.uk/business/committees/committees-a-z/ commons-select/public-accounts-committee/news/bbc-dmi-report-substantive/

Pease, E., \& Dennis, E. (Eds.). (1994). Radio - the forgotten medium. New Brunswick, NJ: Transaction.

Radio Joint Audience Research Limited. (2014). Quarterly listening, First quarter. London: Author. Retrieved October 15, 2014, from http://www.rajar.co.uk/listening/quarterly_listening.php

Starkey, G. (2015). Local radio, going global (Paperback ed.). Basingstoke: Palgrave Macmillan. 